\title{
Finding the Right Article Type for Your Scholarly Work in Pharmacy Education
}

Kristin K. Janke, Ph.D.

University of Minnesota, College of Pharmacy - Twin Cities

\begin{abstract}
Over the last eight years, a number of new article types have been made available to support scholarship in pharmacy education. This commentary aims to describe the evolution of the article types and a process for matching the phase of educational scholarship with available types. Success in publishing requires knowledge of the journals publishing education-related manuscripts, as well as the article types and their specifications. In order to determine the best fit for your manuscript, authors are encouraged to review each journal's guidelines for the various article types.
\end{abstract}

Keywords: scholarship of teaching and learning, education, scholarship, publishing

\section{Tensions in Publishing}

As you have sought opportunities to share scholarly work in education, perhaps you've felt like you're trying to fit a square peg in a round hole. You might have had a compelling and consequential story to tell about a student learning advancement, yet the requirements of the article type require you to twist and contort the message to fit within the stated parameters. Or, perhaps you've been innovating, observing and documenting for a while and a colleague has questioned "Is there enough data yet?" Or maybe you're new to education-related scholarship and you're wondering if your experience merits a paper at all. Indeed, it can be challenging to evaluate our experiences in teaching-related inquiry and to mold and shape those experiences into manuscripts. In addition, it can be difficult to "find the right home" for the manuscripts you create.

Over the past eight years, like authors, journals in pharmacy education have also experienced challenges in bringing forward scholarship. These challenges and frustrations were reflected in comments from authors, assessments from reviewers, observations from editors and, ultimately, in the scope and quality of the articles published. Change in publication options was needed, in order to move educationrelated scholarship forward in pharmacy. In a survey of the landscape, a number of issues emerged. First, the foundation that inspired and supported scholarly work was often sparsely reported and documented. ${ }^{1}$ A space was needed for the discussion of the theories, models and evidence supporting the educational initiatives, as well as the rationale. Second, the testing of educational initiatives/interventions was often celebrated, but the iterations or progress leading up to a major outcomes assessment often did not have a venue. ${ }^{1}$ To encourage others to join in a promising area of inquiry, a place was needed for sharing of the initial, preliminary scholarship that occurred before extensive testing. Finally, despite the passage of time, many instructional challenges in pharmacy education had not developed a solid line of inquiry. ${ }^{1}$ To evolve teaching and learning, questions must be asked and answered, leading to substantive changes in teaching practices, as well as deeper questions for further inquiry. Mechanisms for encouraging and supporting a succession of publications within a line of inquiry were needed.

In response to this examination of the landscape, action was taken. New article types were identified and developed. The general goal was to broaden the academy's notion of education-related scholarship. Attention was specifically given to publishing options for initial and early forms of education-related inquiry. In addition, efforts were placed on creating a menu of article types that would encourage authors to explore and document their inquiries throughout all phases of inquiry. This commentary aims to describe the evolution of the article types and a process for matching the phase of educational scholarship with available types.

\section{New Article Types and Author Support}

The new article types were developed by surveying the landscape in pharmacy education, analyzing pharmacy's publications, consulting publication practices in higher education and examining the literature on education-related scholarship. In particular, they were inspired by MaryEllen Weimer's work, Enhancing Scholarly Work on Teaching and Learning, which analyzes the scholarly literature across the disciplines, outlining the value of various kinds of inquiry and providing exemplars. ${ }^{2}$

In 2014, Innovations in Pharmacy (liP) announced revised guidelines for education-related case study reports and idea papers, as part of its efforts to promote the development of lines of inquiry. ${ }^{1}$ Shortly thereafter, Currents in Pharmacy Teaching and Learning (CPTL) launched Teaching and Learning Matters $^{3}$ (a form of Case Study Report), followed by Quality Improvement and Wisdom of Experience (a form of Reflective Practice) article types. In addition, IiP, CPTL and the American Journal of Pharmaceutical Education (AJPE) have written specifications for education-related Short Communications, although each has a different name for this category, i.e. Note, Experiences in Teaching and Learning and Brief, respectively. Along with new article types, there has been a renewed 
commitment to Commentaries as a mechanism for creating dialogue on education-related issues. ${ }^{4}$ In addition, CPTL has also launched a scholarly blog, CPTL Pulses, as a means to create dialogue. ${ }^{5}$

New and refined options for publishing are exciting, but outlining guidance to authors was only the first step. Support for authors was also required. To this end, CPTL launched Methodology Matters, which regularly releases articles that explore why particular methods may be preferred.$^{6}$ AJPE has launched an annual Joseph T. DiPiro Excellence in Publishing Workshop, which is offered at the American Association of Colleges of Pharmacy (AACP) Annual Meeting. ${ }^{7}$ liP has distilled the literature and provided working definitions of innovation, scholarly teaching and the scholarship of teaching and learning, as well as general review criteria for educationrelated papers. ${ }^{8}$

Indeed, the attention and activity related to scholarship in education has been inspiring and invigorating for many. However, the environment is now more complex. Authors must select an appropriate journal and also find an article type that is a solid fit for the inquiry being shared.

\section{Matching Inquiry to Article Types}

In an attempt to aid thinking about the amount and type of experience, Table 1 describes phases of scholarship and associated article types. Laurie Richlin has described the scholarly process in education as beginning with a problem that the teacher would like to improve or an opportunity they would like to seize. ${ }^{9}$ For faculty that have observed a teaching or learning problem or opportunity, "preliminary" options allow for framing and sharing the idea or observation. This provides vital experience in communicating about the challenge or opportunity, particularly its boundaries, nuances and implications. The preliminary options might also be used to convey an opinion regarding a particular intervention. Of note, these options require a scholarly approach. An informed opinion, appropriate use of terminology, and connections to the existing knowledge base are expected. Being short, these options provide an excellent entry point, allowing an author to publically state their interests and initiate the beginnings of inquiry. The public nature of this phase may even generate contacts that can aid in future phases of the inquiry.

While the preliminary options might focus on the teaching or learning challenge that is motivating the inquiry, the "formulating" option provides a venue for the intellectual work leading up to an educational intervention and its description or evaluation. As Richlin points out, the next step in educational scholarship is studying the work of others. ${ }^{9}$ At this point, some investigators may be inclined to write a review article, drawing together the available literature. This is certainly an option. Those choosing this direction may want to consult the typology of reviews by Grant and Booth, which outlines 14 review types and their methologies. ${ }^{10}$ In addition, it would be prudent to consult the author guidelines and/or editor of the prospective journal to ensure that the type of review written is acceptable to the journal.

Another alternative is to more explicitly move into the "formulating" phase, where literature and experience are used to describe the foundation of the challenge or opportunity and an approach. This writing is characterized by grounding in the theories, models, frameworks and previous investigations, as well as visionary, forward thinking. Moving beyond a standard literature review, these papers make an argument and advocate for an educational approach. They also discuss methods for moving the academy forward. As a result, they may be more tightly tied to the investigator's work by describing the foundation and setting direction. These papers can then be referred to in subsequent papers where elaboration on the foundation is not possible and/or desired.

Following these are the "describing", "testing" and "evaluating" article types, which may be more familiar. Cook, Bordage and Smith have described a continuum of research questions in education and examined published work to determine where efforts have been placed. The categories include description ("What was done?"), justification (“Did it work?") or clarification ("Why or how did it work?"), ${ }^{11}$ with authors advocating for more attention to clarification questions. ${ }^{11,12}$ Although the describing, testing and evaluating article types were not explicitly developed to directly align with description, justification and clarification questions, these article types are well-suited to reporting on these questions.

In the "describing" area, these options are characterized by the focus on description and by a scale and scope that does not demand lengthy communication. Journals will vary on the focus of the content of their Short Communication article type. For instance, CPTL's Experiences in Teaching and Learning generally focuses on application, implementation, modification or improvement of a previously developed teaching and learning approach. ${ }^{13}$ In alignment with its focus on innovation, liP's Note focuses on pilot or early stage work that has not been previously well documented and has implications for further work in the field. ${ }^{14}$

The "testing" phase, Original Research, is well known. In the quantitative tradition, it involves hypothesis driven inquiry aimed at building upon and advancing generalizable knowledge related to pharmacy education. With its focus on strong, prospective design decisions and rigorous methods, Original Research is well-suited to "Did it work?" questions that are investigated through experimental designs. However, presuming strong design and methods, it can also be used for qualitative inquiry and/or "Why or how did it work?" questions. It should be noted that both AJPE (www.ajpe.org) and CPTL (www.pharmacyteaching.com) offer a Short 
Communication version of Original Research. Prospective authors are directed to the respective websites for further information.

Article types aligned with the "evaluating" phase are generally focused on strong prospective design and detailed, rich reporting, incorporating multiple perspectives or vantage points. Similar to the qualitative tradition for case study, the Case Study Report (CSR) seeks to illuminate the complexity of the teaching or learning challenge (or opportunity) and the attempted response. To do this, multiple data sources are drawn together and triangulated. Again, journals will vary on the stated foci for their CSRs. liP's Case Study Report focuses on "preliminary, novel, or unsuspected results of an innovative instructional technique, method, strategy or approach" with the goal of inspiring future use or investigation. ${ }^{1} C P T L$ 's Teaching and Learning Matters has a similar goal with its focus on the wisdom that is gained through a scholarly approach to teaching and describing advancements in teaching and learning practices. $^{3}$ Clinicians may be familiar with case studies from the clinical literature where there is a tight focus on a particular patient. In education, the "case" is the teaching-learning situation. The application is similar in that the subject of inquiry may be new and documenting details is important in moving inquiry forward. A CSR is also well suited for probing clarification questions, specifically "Why and how did it work?"

As experience is gained over time, two additional phases open for scholarship. The "improving" phase of scholarship focuses on longitudinal iterations, the application of continuous quality improvement methods and the results of a quality improvement (QI) inquiry. The "reflecting" phase allows investigators to take a reflective practice approach to teaching by applying a reflective model to epochal or cumulative experience, using substantive analysis and interpretation that generates insights of value to others. ${ }^{15}$ Reflecting on the practice of teaching may uncover new challenges or opportunities and result in cycling back to preliminary and formulating phases.

\section{Conclusions}

In selecting article types, prospective authors should consider the existing knowledge base in education, as well as their own personal experience with the area of inquiry. There is value in articulating the problem, establishing the foundation, and describing, testing and evaluating. There is also value in attempting additional iterations and fine tuning, as well as utilizing reflective practice to advance teaching. In particular, there is a need to move beyond description and justification to clarification questions, such as "Why and how did it work?"11,12 With the breadth of article types available, authors can examine the current phase of inquiry and contribute to the teaching and learning knowledge base by matching experience to the available article types. The existing breadth of publishing opportunities respects and encourages the need to dive deep into inquiry and pursue successive questions that establish a line of inquiry.

Acknowledgements: The author thanks the Education Team of Innovations in Pharmacy including, Andrea Franks, Pharm.D., Katherine Kelley, Ph.D., Lara Kerwin, Pharm.D., Claire Kolar, Pharm.D., Ph.D., and Michael Nelson, Ph.D., for their comments on an earlier version of this manuscript.

Creative Commons License: $\underline{\mathrm{CC} \text { BY-NC}}$

Disclosures: The author is Executive Associate Editor for Currents in Pharmacy Teaching and Learning and Editor for Innovations in Pharmacy with responsibility for the Education Section. 
Table 1. Matching phase of inquiry with available article types

\begin{tabular}{|c|c|c|}
\hline $\begin{array}{l}\text { Scholarly Approach } \\
\text { or Phase }\end{array}$ & Description & Article Type (Journal) \\
\hline Preliminary & $\begin{array}{l}\text { Articulating teaching/learning challenges to encourage } \\
\text { scholarly dialogue. }\end{array}$ & $\begin{array}{l}\text { Pulses Scholarly Blog (CPTL), } \\
\text { Commentaries (all journals) }\end{array}$ \\
\hline Formulating & $\begin{array}{l}\text { Describing the foundation of a learning challenge, } \\
\text { teaching technique or educational approach and } \\
\text { advocating for methods to move it forward. }\end{array}$ & Idea Paper (IiP) \\
\hline Describing & $\begin{array}{l}\text { Reporting on a teaching experience, e.g. students were } \\
\text { satisfied and they performed well. "What was done?" }\end{array}$ & $\begin{array}{l}\text { Brief (AJPE), Experiences in Teaching and } \\
\text { Learning (CPTL), Note (liP) }\end{array}$ \\
\hline Testing & $\begin{array}{l}\text { Using experimental designs to determine "Did it work?" } \\
\text { and "How well did it work?" }\end{array}$ & Original Research (all journals) \\
\hline Evaluating & $\begin{array}{l}\text { Triangulating multiple data types from multiple sources to } \\
\text { illuminate the complexity in education e.g. "Why did it } \\
\text { work?" "How did it work?" }\end{array}$ & $\begin{array}{l}\text { Teaching and Learning Matters (CPTL), } \\
\text { Case Study Report (IiP) }\end{array}$ \\
\hline Improving & $\begin{array}{l}\text { Describing cycles of enhancements to teaching/learning } \\
\text { over time to address quality improvement questions. }\end{array}$ & Quality Improvement (CPTL) \\
\hline Reflecting & $\begin{array}{l}\text { Generating insights of value to others through analysis } \\
\text { and interpretation of teaching experience using reflective } \\
\text { practice. }\end{array}$ & Wisdom of Experience (CPTL) \\
\hline
\end{tabular}

AJPE: American Journal of Pharmaceutical Education

CPTL: Currents in Pharmacy Teaching and Learning

liP: Innovations in Pharmacy 


\section{References}

1. Janke KK, Kolar C. Promoting Scholarly Lines of Inquiry in Pharmacy Education Through Idea Papers and Case Study Reports. Inov Pharm. 2014;5(3). doi:10.24926/iip.v5i3.344.

2. Weimer M. Enhancing Scholarly Work on Teaching \& Learning. San Francisco, CA: Jossey-Bass; 2006.

3. Brown MC, Schneider SR, Janke KK. Inviting manuscripts to Teaching and Learning Matters. Curr Pharm Teach Learn. 2014;6(6):749-751. doi:10.1016/j.cptl.2014.08.004.

4. Kolar C, Harrell TK, Janke K. Would you care to commentary on that? Curr Pharm Teach Learn. 2016;8(3):267-268. doi:10.1016/j.cptl.2016.02.022.

5. About Pulses. CPTL Pulses. https://cptlpulses.com/. Published 2017. Accessed January 16, 2018.

6. Peeters MJ, Cor MK, Harpe SE, Janke KK. Announcing a new section-Methodology Matters. Curr Pharm Teach Learn. 2015;7(5):563-564. doi:10.1016/j.cptl.2015.06.003.

7. Brazeau GA. Report of the Journal Editor. Am J Pharm Educ. 2016;80(4):S1. doi:10.5688/ajpe804S1.

8. Janke KK, Kolar C. Recognizing and Disseminating Innovations in Scholarly Teaching and Learning to Support Curricular Change. Inov Pharm. 2014;5(3).

9. Richlin L. Scholarly Teaching and the Scholarship of Teaching. New Dir Teach Learn. 2001;2001(86):57-68. doi:10.1002/tl.16.

10. Grant MJ, Booth A. A typology of reviews: An analysis of 14 review types and associated methodologies. Health Info Libr J. 2009;26(2):91-108. doi:10.1111/j.1471-1842.2009.00848.x.

11. Cook DA, Bordage G, Schmidt HG. Description, justification and clarification: A framework for classifying the purposes of research in medical education. Med Educ. 2008;42(2):128-133. doi:10.1111/j.1365-2923.2007.02974.x.

12. Norman G. Why? Adv Heal Sci Educ. 2017;22(3):577-580. doi:10.1007/s10459-017-9780-3.

13. Currents in Pharmacy Teaching and Learning. Author Information Pack. https://www.elsevier.com/wps/find/journaldescription.cws_home/718643?generatepdf=true. Accessed January 17, 2018.

14. Innovations in Pharmacy - Education Section. Article Types. https://drive.google.com/file/d/1ZljQfOwJP9qUjfSg6BwZPBbmDguAatfV/view. Accessed January 19, 2018.

15. Janke KK, Cox CD, Lucas C. Inviting articles for and on the Wisdom of Experience. Curr Pharm Teach Learn. August 2017. doi:10.1016/j.cptl.2017.06.008. 